\title{
Application of by Product of a Steel (Steel Slag) As Fractional Additional of Mixture Coarse Aggregate in Concrete
}

\author{
Engr. Muhammad Ali Safdar \\ (P.G. Scholar) \\ Department of Civil Engineering, \\ Iqra National University (INU), Peshawar, Pakistan \\ Engr. Mehran Mohammad \\ Department of Civil Engineering, \\ Iqra National University (INU), Peshawar, Pakistan \\ Engr. Sohail Ahmad \\ Department Of Civil Engineering, \\ CECOS University of Science and Technology, Peshawar, Pakistan \\ Engr. Syed Waqar Ali Shah \\ Department Of Civil Engineering, \\ Iqra National University (INU), Peshawar, Pakistan
}

\begin{abstract}
As we already know that human's population are increasing day by day and in order to meet their various transportation-al and housing needs construction is going on at a very faster rate and there might be a chance that usage of natural coarse aggregate become less because natural mountains are being damaged due to drilling or by blasting. In this investigation an attempt is being made to find a solution in which original strength and durability can be obtained by usage of by-product of steel (Steel Slag). The purpose of this investigation is to examine analytically, the "APPLICATION OF STEEL SLAG AS FRACTIONAL ADDITIONAL OF COARSE AGGREGATES" examined by replacement of natural coarse aggregates by different ratio of steel slag at $20,40,60,80$ and $100 \%$ by using the mix design of class $A$ concrete and its strength was more than $4500 \mathrm{psi}$.The specimen standard cylinders size and beams (8 inch,8 inch and 21 inch ) size were used and they were tested at 7,14 and 28 days interval .It was properly water cured .Various concrete tests were being performed ,In order to find out the actual behaviour of concrete and the tests were compressive, split, flexural and slump test. The test graph shows that there is a wide variation in compressive, split, flexural and slump strength of natural coarse aggregate replaced by steel slag for 7,14 and 28 days.
\end{abstract}

Keywords: Steel Slag, Aggregates, Concrete, Compressive Strength, Flexural Strength.

\section{INTRODUCTION}

Concrete is considered as a supremely important and the biggest building material of this planet earth. For development effort, there is no second and third alternative material available and only concrete is being used everywhere around the globe. Hence its usage is considered as one of the universally accepted as a basic building material and there is a lot of construction is going around, which increased its demand and there is an estimated usage of concrete that is concrete being used at almost 5 billion tons per annum, universally none of any material being used so far for development effort and it makes biggest raw material ever used in any manufacturing production for development works. 
As we already know that natural raw materials reserves are going vacant and a need is being created that if natural resources are going down then how we can use produce concrete the problem is solved by a researcher, in which they use certain replacement within concrete composition which not only solved raw material but it also strength and durability without natural raw materials. For this investigational study, Concrete mix design of 4500 psi was prepared and Steel slag was used as a specimen at 0,20,40,60,80 and 100\%. replacing course aggregates. Compression, Split, Flexural and slump test were performed and Concrete Cylinders, Concrete beams were casted and they were tested at 7,14 and 28 days. Then their result was discussed.

\section{LITERATURE REVIEW}

A by-product of a steel (steel slag) has been used to store pavements for culminating around one hundred years. Since it was found that the change from the production of steel might be compacted and built into a thing that took after beat vibration, particular starter s similar compressive quality central and divided logbook groundwork was finished to pick the help of this left-over thing. It was available that, all things considered, survive, genuine ended, vesicular, set exteriors to give the particle work, and if really smoothed, the high relentless quality fundamental for respectable valuable blacktops. The misuse of steel slag is all around involved as a piece of the coarse total segment of the blend at a rate of twenty (20) percent (\%) to seventy-five (75) percent (\%), subordinate upon the use of the blend (Kalpana and Pradheepa, 2014).

Mulled over that it supported not shake hard to a method with the solid made with a byproduct of a steel (steel slag) totals. In addition, an elite of the basic perspectives in the stone hard combination is the number of air vacuums out of sight. Airborne vacuums influence the H20 to submerge the gaps, which thusly diminish high inner nerves and along these lines, diminish cut back measure part in the structure. Value of concrete does not have any true-blue modification in a setting of increment of slag mean. Compressive nature of numerous combinations demonstrates utilitarian differentiation in around ten (10) percent (\%). The constituent of slag controls the alteration in predominance" Kotahi and Malathay $(2013,29)$.

Presented that prevailing to driving all the starter investigating it, it was watched that thirty (30) percent (\%) dislodging of fine aggregate with by-product of a steel (steel slag) by-product of a steel (steel slag) finished up being phenomenal in weight quality, anyway the strong having by-product of a steel (steel slag) and fine aggregate in for all intents and purposes indistinguishable degrees wound up being to be inefficient. The compressive thought of the strong development as the proportion of replacement augments up to thirty (30) percent (\%). Over that proportion of replacement, the regular compressive quality diminishments. Accordingly, the perfect rate of substitution suggested is thirty (30) percent (\%) in which the quality got is $27 \mathrm{~N} / \mathrm{mm} 2$ for $20 \mathrm{~N} / \mathrm{mm} 2$ audit of security. The worth of progress depends on the costs of protest or substance. Since by-product of a steel (steel slag) is without open of value, the Price of strong decreases, as the rate of substitution increases. In this manner, when dynamically the recurrence of substitution would be higher than naturally their future increment in esteem would likewise happen (Kaviya and Geeta,2014).

The displacing of Mixture of rocks (coarse aggregate) with a by-product of a steel (steel slag) has extended the compressive quality, split determination and flexural nature of the bond. The perfect percentage of a by-product of a steel (steel slag) as far as anyone knows was sixty (60) percent (\%). The change in the percentage of a by-product of a steel (steel slag) in strong shows higher strength to harming and sulphate strike. Accurate, when this improved regard will be used, its qualities would be an excellent blowing quality and more excellent strong 
when showed up particularly in association with standard bond and extra things material price up to $10 \%$ (Thangaselvi, 2015).

Conferred that the perfect estimation of compressive quality can be ace by twenty (20) percent (\%) replacement of steel slag like manner, the perfect approximation of flexural quality with twenty (20) percent (\%) replacement of by-product of a steel (steel slag) was $4.93339 \mathrm{~N} / \mathrm{mm} 2$ and the perfect approximation of split versatility with twenty (20) percent (\%) replacement of by-product of a steel (steel slag) was $2.959999 \mathrm{~N} / \mathrm{mm} 2$ for 19.999 N/mm2 outline of bond" (Abrol et al,2016).

\section{Steel slag}

\section{MATERIALS USED}

In this research the steel slag is taken from FF steel, Hayatabad, Phase 7, Peshawar. Nowadays steel is being used everywhere in various forms universally in various form. The steel slag is one of the outgrowth productions of steel, which is made during the departure of hot, Boiled steel from scums in steel-production factories. The slag is formed, when molten steel boiled and formed a shape of molten liquid in a furnace, it is a mixture of silicates and oxides, which come in a solid form after cooling freezing Steel is tough and resist any type of load. Steel has one good quality that it can resist any type of load and due to this quality it have a greater demand in industries. As we already know that $30 \%$ of useful steel is obtained while $70 \%$ wasteful steel is being dumped into various places. Which creates a lot of environmental and hazard problem universally. There should be a mechanism develop for steel slag waste, whether it's by product should be used or dumped in such a place that it can be less harmful for human and others

\section{Mix design of concrete}

The mix design of a concrete is prepared according to American Concrete Standard (ACI) and it have a strength more than 4500 psi strength

Table 1. Mix design of 4500 psi

\begin{tabular}{|c|c|c|c|c|c|}
\hline Blend & $\begin{array}{c}\text { Cement } \\
\text { (Binding } \\
\text { Material) }\end{array}$ & $\begin{array}{c}\text { By product of a } \\
\text { steel (steel } \\
\text { slag) }\end{array}$ & $\begin{array}{c}\text { Mixture of small } \\
\text { particles of grains(sand) } \\
\text { (Kg) }\end{array}$ & $\begin{array}{c}\text { Mixture of rocks } \\
\text { (coarse aggregate) }\end{array}$ & $\boldsymbol{H}_{2} \mathbf{O}$ \\
\hline Cs & 500 & 0 & 830 & 1052 & 187 \\
\hline Cs $20 \%$ & 500 & 210.4 & 830 & 841.6 & 187 \\
\hline CS $40 \%$ & 500 & 420.8 & 830 & 631.2 & 187 \\
\hline Cs $60 \%$ & 500 & 631.2 & 830 & 420.8 & 187 \\
\hline Cs $80 \%$ & 500 & 841.6 & 830 & 210.4 & 187 \\
\hline Cs $100 \%$ & 500 & 1052 & 830 & 0 & 187 \\
\hline
\end{tabular}

$\mathrm{Cs}=$ Control Sample without replacement of coarse aggregate with Steel Slag Cs 20\%= Control Sample replacing 20\% of coarse aggregate with Steel Slag Cs $40 \%=$ Control Sample replacing $40 \%$ of coarse aggregate with Steel Slag Cs $60 \%=$ Control Sample replacing $60 \%$ of coarse aggregate with Steel Slag Cs $80 \%=$ Control Sample replacing $80 \%$ of coarse aggregate with Steel Slag Cs $100 \%=$ Control Sample replacing $100 \%$ of coarse aggregate with Steel Slag

\section{Compressive Test}

\section{METHODOLOGY}

The compression strength trial was performed according to ASTM C 39 on seven, fourteen (14) and Twenty-eight (28) days. On a specific day, compression trial was performed for each chamber. A mechanism was defined that for each chamber that a smooth layer was applied to it 
in order to make its surface smooth and level. Chambers was placed in a compressive testing Devices and its weight was determined for each chamber after its breaking. The compression weight for each chamber was obtained by dividing weight at which a chamber breaks by the region of a chamber.

Compressive quality $=$ stack $/$ area $=\mathrm{F} / \mathrm{A}$

Figure 1: Cylinder are going to be crushed in a compression testing machine

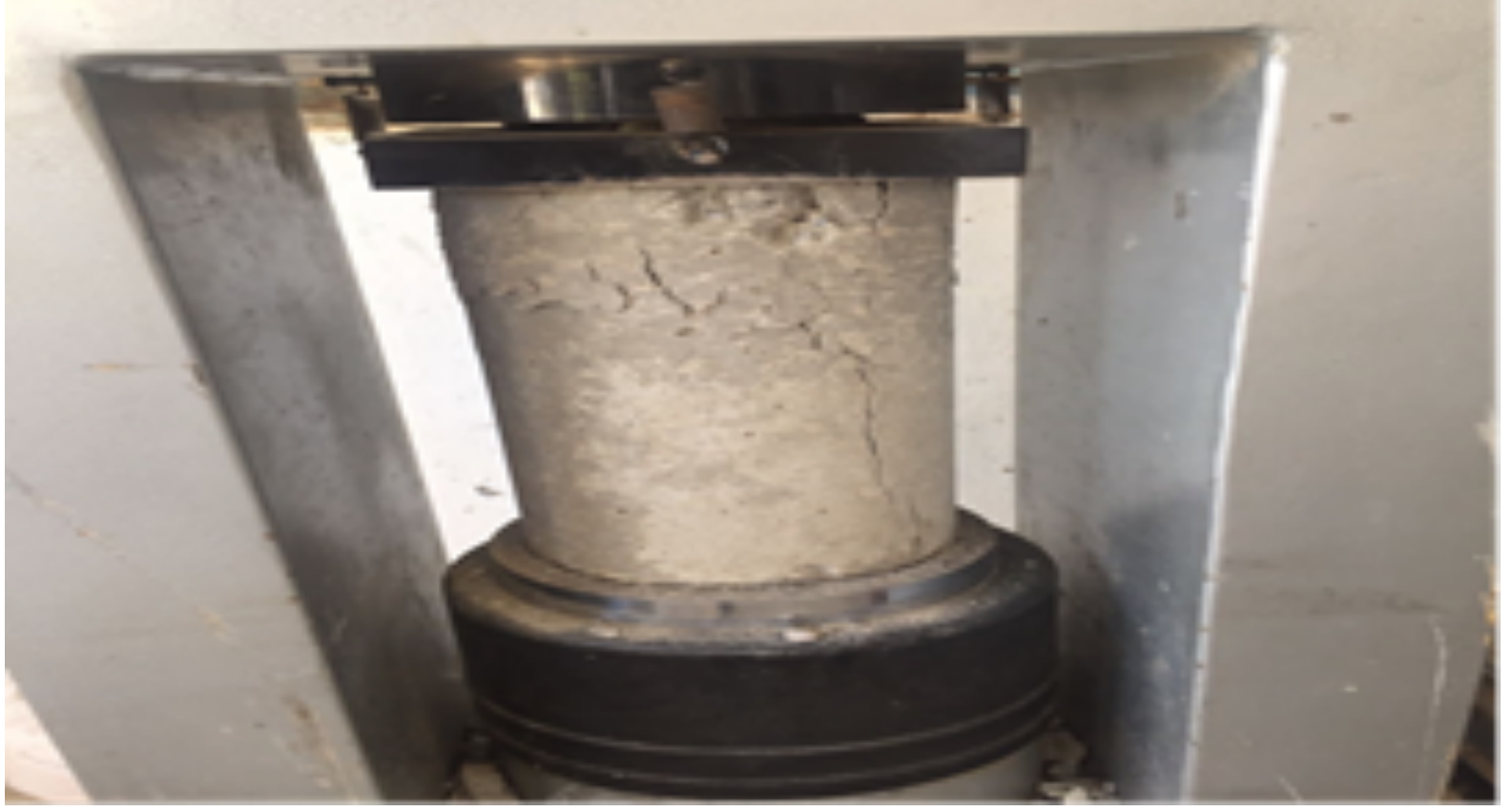

Different cement blends consuming diverse rates of steel slag/squanders by means of fractional substitution of coarse total stood tried for seven (7), fourteen (14) and twenty-eight (28) days of curing quality. The fine total be situated supplanted by shifting rates of steel slag/squanders, for example, twenty (20) percent (\%), forty (40) percent \%), sixty (60) percent (\%), eighty (80) percent (\%) and hundred (100) percent (\%). An aggregate of 45 chambers was thrown for the compressive quality trial and 3 trial s were tried for every substitution in addition day. The normal of these three (3) chambers, when tried at their separate age, was then taken as concrete compressive quality. The blend extent was $1,1.78,1.36,0.52$ with a folio proportion of 0.39 .

Table 2. Comparison of 7,14 and 28-days compressive strength with percent expansion respectively

\begin{tabular}{|c|c|c|c|}
\hline $\begin{array}{c}\text { Distinctive types of } \\
\text { blend }\end{array}$ & Substituent Equal & Seven (7) days & Percent (\%) expansion \\
\hline CS & 0 & 2973.51 & - \\
\hline Cs $20 \%$ & 20 & 3008.37 & 1.16 \\
\hline Cs $40 \%$ & 40 & 3237.09 & 7.07 \\
\hline Cs $60 \%$ & 60 & 3370.83 & 3.97 \\
\hline Cs $80 \%$ & 80 & 3150.01 & 7.02 \\
\hline Cs $100 \%$ & 100 & 3040.43 & 3.61 \\
\hline
\end{tabular}

Compressive Strength for 7 days

According to above table ,The compressive test was done for Twenty ,Fourthly ,Sixty ,Eighty and Hundred percent (\%) at seven day In which coarse aggregate was replaced by steel slag by above percent .At zero percent replacement, The compressive strength is 2973.51 and there is no percent replacement because its consider first in all .Secondly ,At twenty percent replacement ,Its 
strength is 3008.37 and its 1.16 increase in its strength then zero percent replacement, Thirdly ,At forty percent replacement, Its strength is 3237.09 and it is $7.07 \%$ more than twenty percent replacement .Fourthly, At sixty (60) percent, Its compressive strength test is 3370.83 and its percent increase is $3.97 \%$ less than the fourthly (40) replacement .Fifth, At eighty (80) replacement. Its compressive strength test is 3150.01 and its percent increase is 7.02 . Which is more than sixty (60) \% replacement but less then fourthly (\%) replacement. Six, at hundred (100) replacement, its compressive strength is 3040.43 and it is 3.61 . Which is less then eighty, sixty, fourth percent but more than twenty percent replacement.

Hence sixty percent replacement is higher in compressive strength then other replacement

Figure 1. Graphical representation of Compressive Strength for 7 days

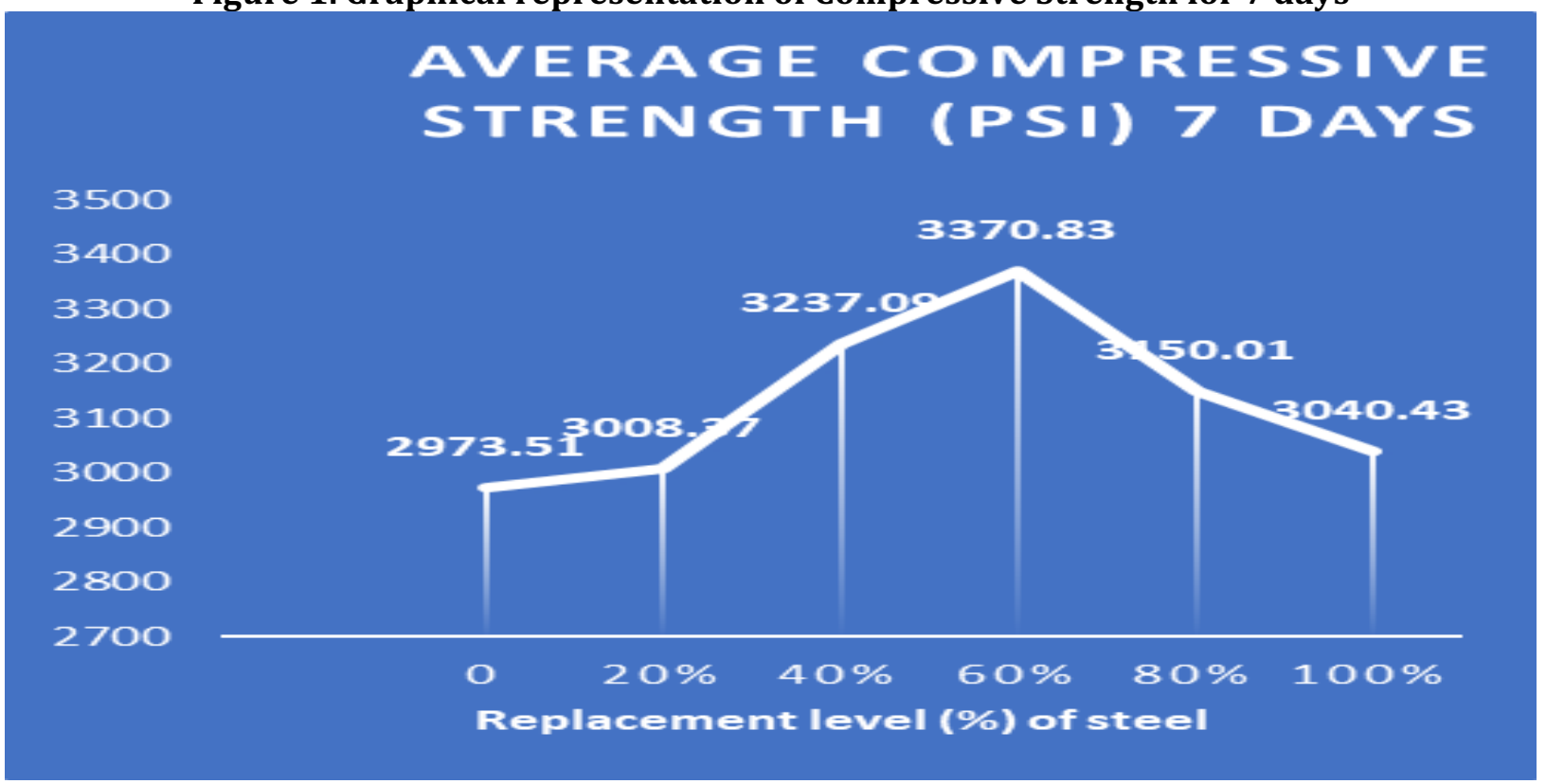

Above graph shows that it gives 3370.83 strength, which is higher in strength then all replacement

Table 3. Compressive Strength for 14 days

\begin{tabular}{|c|c|c|c|}
\hline $\begin{array}{c}\text { Distinctive types of } \\
\text { blend }\end{array}$ & Substituent Equal & Fourteen (14) days & Percent (\%) expansion \\
\hline CS & 0 & 3570.08 & - \\
\hline Cs $20 \%$ & 20 & 3623.75 & 1.49 \\
\hline Cs $40 \%$ & 40 & 3857.03 & 6.05 \\
\hline Cs $60 \%$ & 60 & 4027.23 & 4.23 \\
\hline Cs $80 \%$ & 80 & 3765.93 & -6.94 \\
\hline Cs $100 \%$ & 100 & 3545.66 & -6.22 \\
\hline
\end{tabular}

According to above table, The compressive test was done for Twenty ,Fourthly, Sixty, Eighty and Hundred percent (\%) at fourteen day In which coarse aggregate was replaced by steel slag by above percent .At zero percent replacement, The compressive strength is 3570.08 and there is no percent replacement because its consider first in all .Secondly, At twenty percent replacement, Its strength is 3623.75 and its 1.49 increase in its strength then zero percent replacement ,Thirdly ,At forty percent replacement, Its strength is 3857.03 and it is $6.05 \%$ more than twenty percent replacement.Fourthly ,At sixty (60) percent, Its compressive strength test is 4027.23 and ,Its percent increase is $4.23 \%$ less than the fourthly (40) replacement .Fifth, At eighty (80) replacement.Its compressive strength test is 3765.93 and its percent increase is -6.94. Which is more than sixty (60) \% replacement but less then fourthly (\%) replacement.Six, At hundred (100) 
replacement, Its compressive strength is 3545.66 and it is -6.22 .Which is less then eighty ,sixty, fourth percent and twenty percent replacement.

At fourteen days, its sixty percent replacement is higher in compressive strength then other replacement

Figure 2. Graphical Representation of Compressive strength for fourteen days

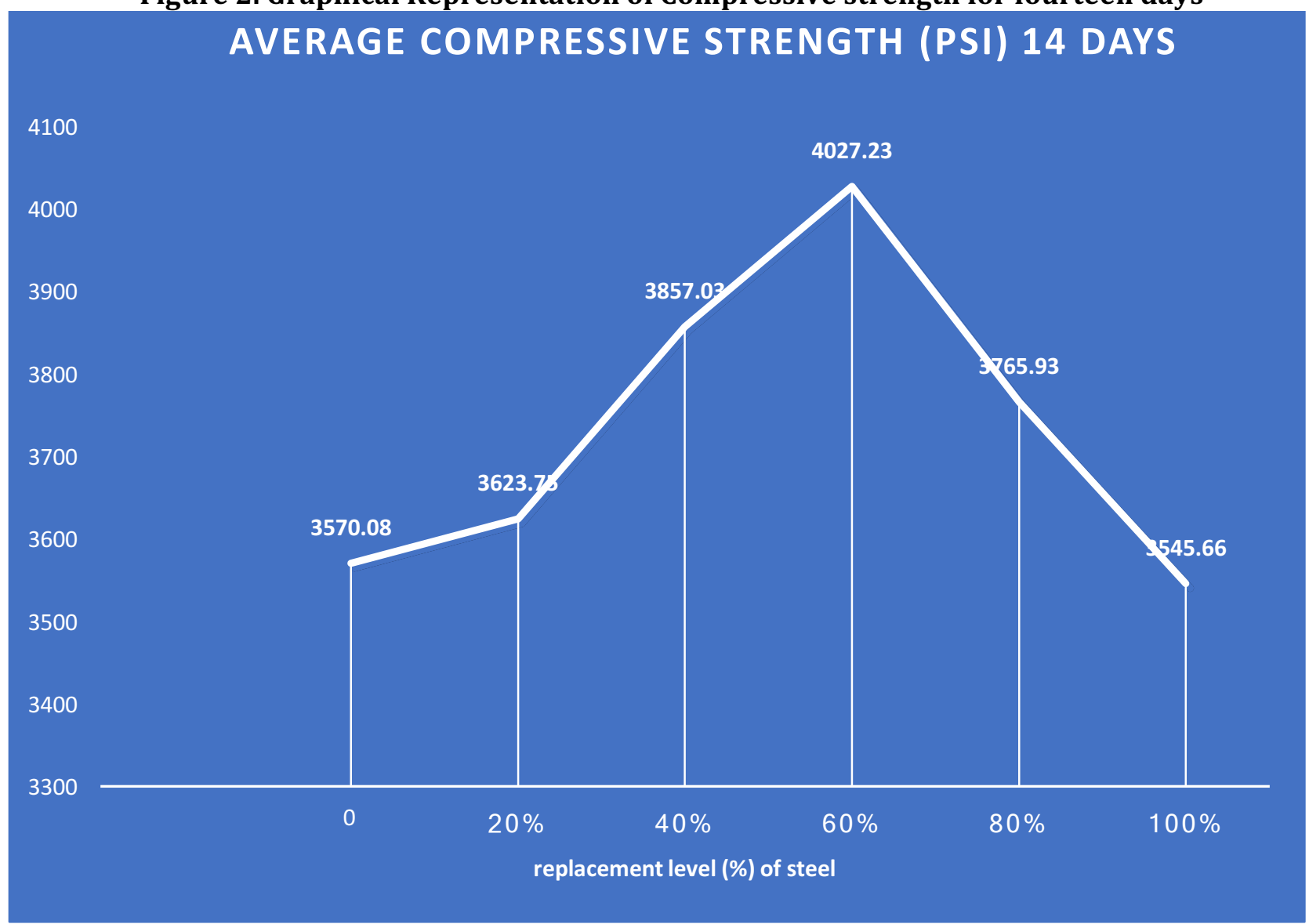

According to figure 1.3 its graphical representation of average compressive at fourteen days is 4027,23 at sixty percent replacement, which is higher than then other replacement. 
Figure 3. Average Compressive Strength of 28 days

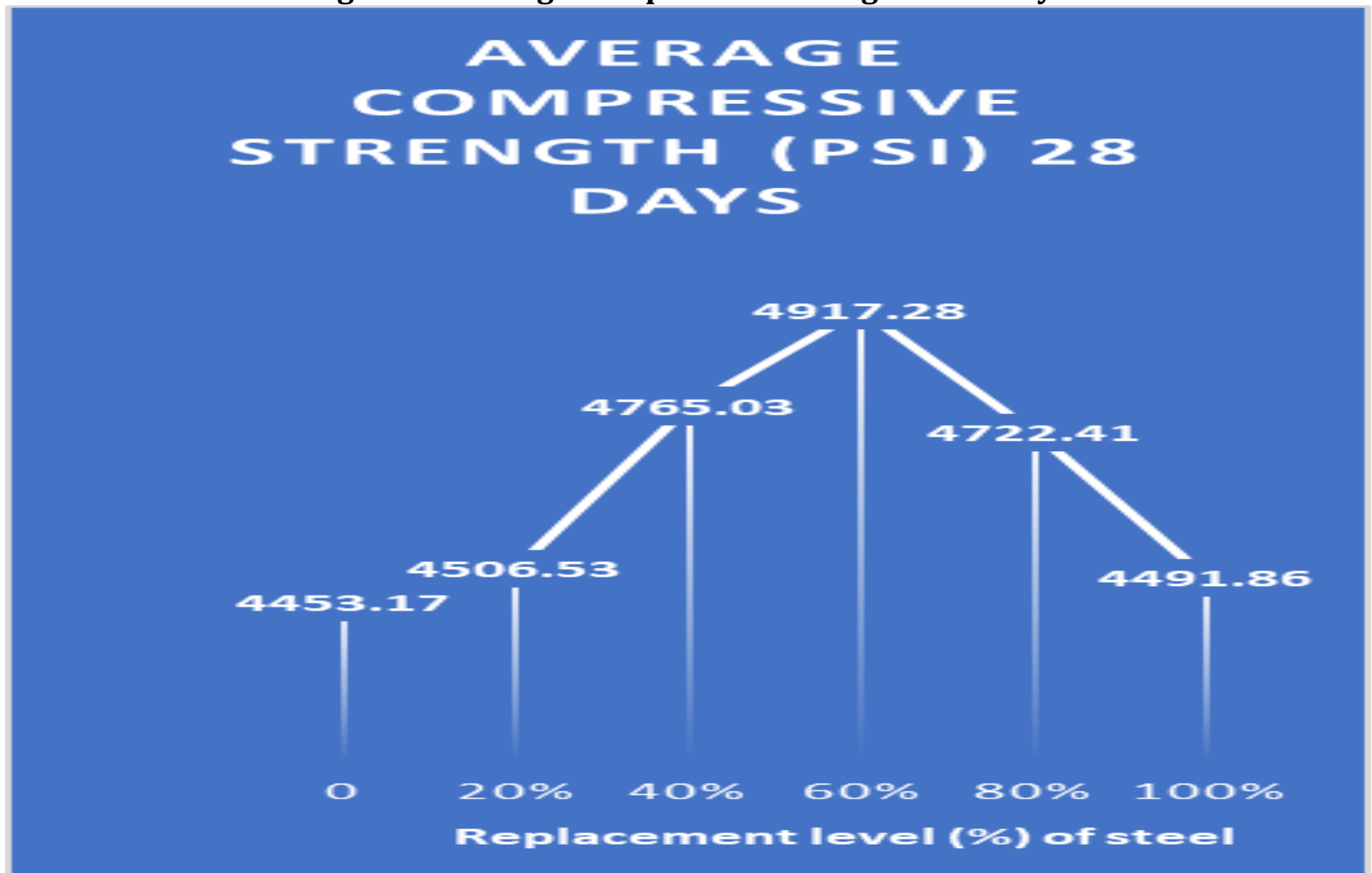

According to figure 1.4 its graphical representation of average compressive at twenty-eight days is 4917.28 at sixty percent replacement, which is higher than then other replacement.

Table 4. Compressive Strength for 28 days

\begin{tabular}{|c|c|c|c|}
\hline $\begin{array}{c}\text { Distinctive types of } \\
\text { blend }\end{array}$ & Substituent Equal & $\begin{array}{c}\text { Twenty eight (28) } \\
\text { days }\end{array}$ & $\begin{array}{c}\text { Percent (\%) } \\
\text { expansion }\end{array}$ \\
\hline CS & 0 & 4453.17 & - \\
\hline Cs $20 \%$ & 20 & 4506.53 & 1.19 \\
\hline Cs $40 \%$ & 40 & 4765.03 & 5.43 \\
\hline Cs $60 \%$ & 60 & 4917.28 & 3.097 \\
\hline Cs $80 \%$ & 80 & 4722.41 & -4.13 \\
\hline$C s 100 \%$ & 100 & 4491.86 & -5.14 \\
\hline
\end{tabular}

According to above table ,The compressive test was done for Twenty, Fourthly, Sixty ,Eighty and Hundred percent (\%) at Twenty eight (28) day In which coarse aggregate was replaced by steel slag by above percent. At zero percent replacement, The compressive strength is 4453.17 and there is no percent replacement because its consider first in all .Secondly, At twenty percent replacement, Its strength is 4506.53 and its 1.19 increase in its strength then zero percent replacement, Thirdly, At forty percent replacement, Its strength is 4765.03 and it is $5.43 \%$ more than twenty percent replacement. Fourthly ,At sixty (60) percent, Its compressive strength test is 4917.28 and ,Its percent increase is $3.097 \%$ less than the fourthly (40) replacement.Fifth, At eighty (80) replacement. Its compressive strength test is 4722.41 and it's percent increase is -4.13. Which is less than all replacement .At hundred (100) replacement, Its compressive strength is 4491.86 and it is $-\mathbf{5 . 1 4}$.Which is less then all replacement at twenty-eight days, its sixty percent replacement is higher in compressive strength then other replacement.

\section{Split Tensile Strength}

As we know that concrete is weak in tension and strong in compression due to which concrete is presumably will face ductile breaking in field condition. In this manner, it ends up critical to decide the solid split rigidity. Split rigidity of the solid example was governor led by ASTM C 
496 trial technique. This trial is utilized to locate the elasticity of cement. The rigidity of the solid is decided in a roundabout way from a split barrel trial. The rigidity of the barrel computed by the below equations.

$\mathrm{S}=2 \mathrm{f} / \pi \mathrm{DL}$

$\mathrm{f}=$ split rigidity

$\mathrm{P}=$ stack"

$\mathrm{D}=$ measurement of a barrel

$\mathrm{L}=$ traverse of the chamber

Figure 4. Cylinder is going to be crushed in a lab

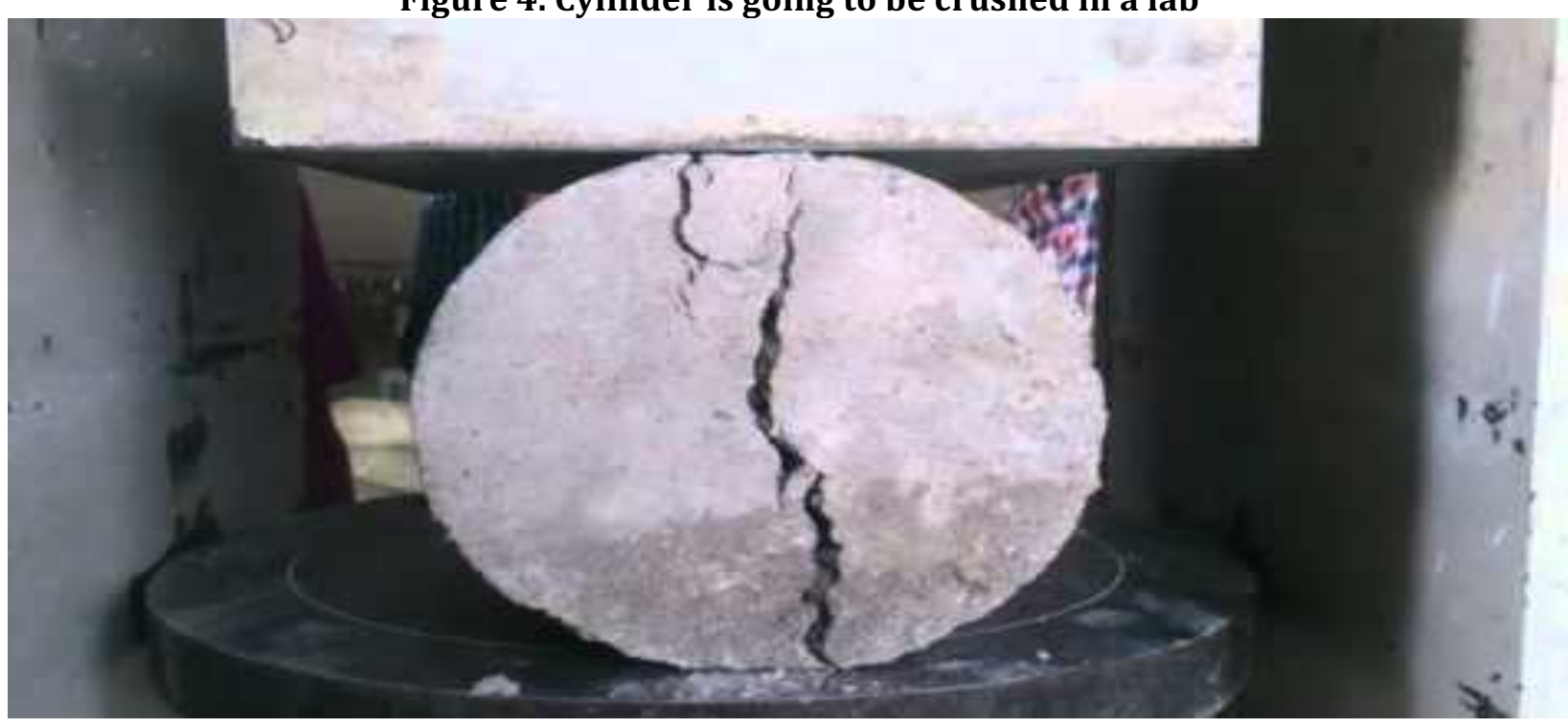

Table 5. Split Cylinder Strength Test for 28 days

\begin{tabular}{|l|c|c|}
\hline Distinctive types of blend & Substitution Equal & split tensile strength ( psi) \\
\hline Cs & 0 & 474.26 \\
\hline Cs $20 \%$ & 20 & 483.21 \\
\hline Cs $40 \%$ & 40 & 513.86 \\
\hline Cs $60 \%$ & 60 & 529.61 \\
\hline Cs $80 \%$ & 80 & 481.43 \\
\hline Cs $100 \%$ & 100 & 469.67 \\
\hline
\end{tabular}

According to above table facts and figures Split Cylinder test was done on different concrete composition specimen varies from Twenty (20) percent to Hundred (100) percent \% steel slag. In them concrete composition having sixty (60) percent have highest value in all of them. 


\section{Figure 5. Graphical representation of split for twenty-eight (28) days}

\section{SPLIT TENSILE STRENGHT FOR 28 DAYS}

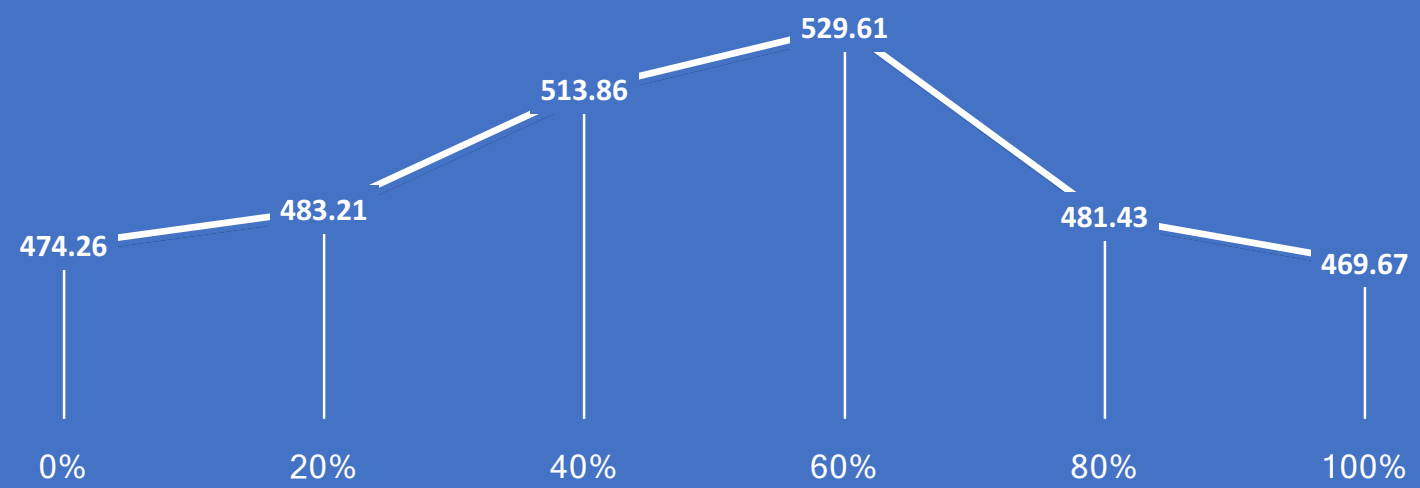

REPLACEMENT LEVEL (\%)

The sixty (60) percent steel slag gives 529.61

The different cement blends having distinctive rates of steel slag /squanders as incomplete substitution of coarse total was tried for 28 days of curing quality. The coarse total was supplanted with differing rates of steel slag/squanders i.e. twenty (20) percent (\%), forty (40) percent (\%), sixty (60) percent (\%), eighty (80) percent (\%) and hundred (100) percent (\%). An aggregate of 18 barrels were threw for the part schedule trial and 3 trials were tried for every substitution and day time. The normal of these three (3) barrels. When tried at their individual age was then taken as solid split rigidity.

\section{Flexural Test}

The flexural trial is performed so as to discover bond quality that how much a material can oppose a quality. This trials are performed on a said material until the point when it fizzles and it is best to be utilized for in-flexible material. The flexural trial was performed by ASTM C78.

Figure 6. Flexural test is going on a beam in a laboratory

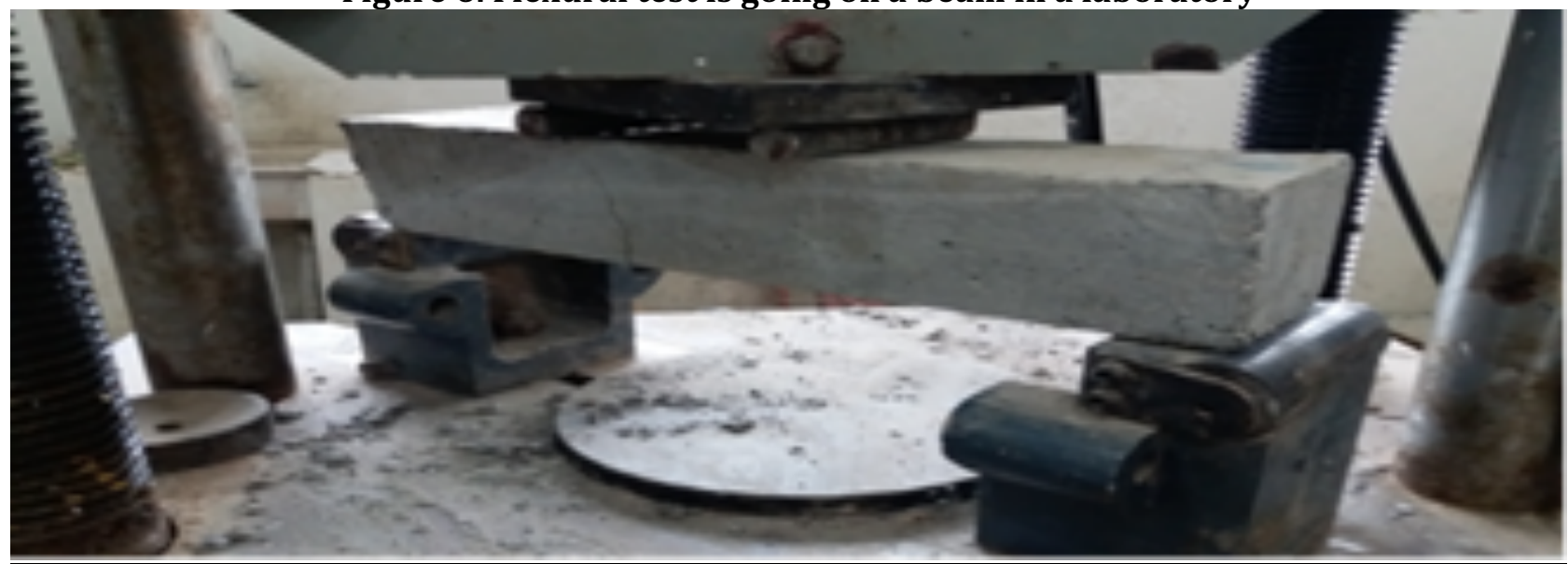


Table 6. Shows Flexural Strength for 28 days

\begin{tabular}{|c|c|c|}
\hline Type of Mix & Extra Level & Flexural strength (psi) \\
\hline Cs & $0 \%$ & 1251.60 \\
\hline Cs $20 \%$ & $20 \%$ & 1269.01 \\
\hline Cs $40 \%$ & $40 \%$ & 1316.87 \\
\hline Cs $60 \%$ & $60 \%$ & 1356.03 \\
\hline Cs $80 \%$ & $80 \%$ & 1327.02 \\
\hline Cs $100 \%$ & $100 \%$ & 1287.87 \\
\hline
\end{tabular}

Figure 7. Graphical representation of split for twenty-eight (28) days

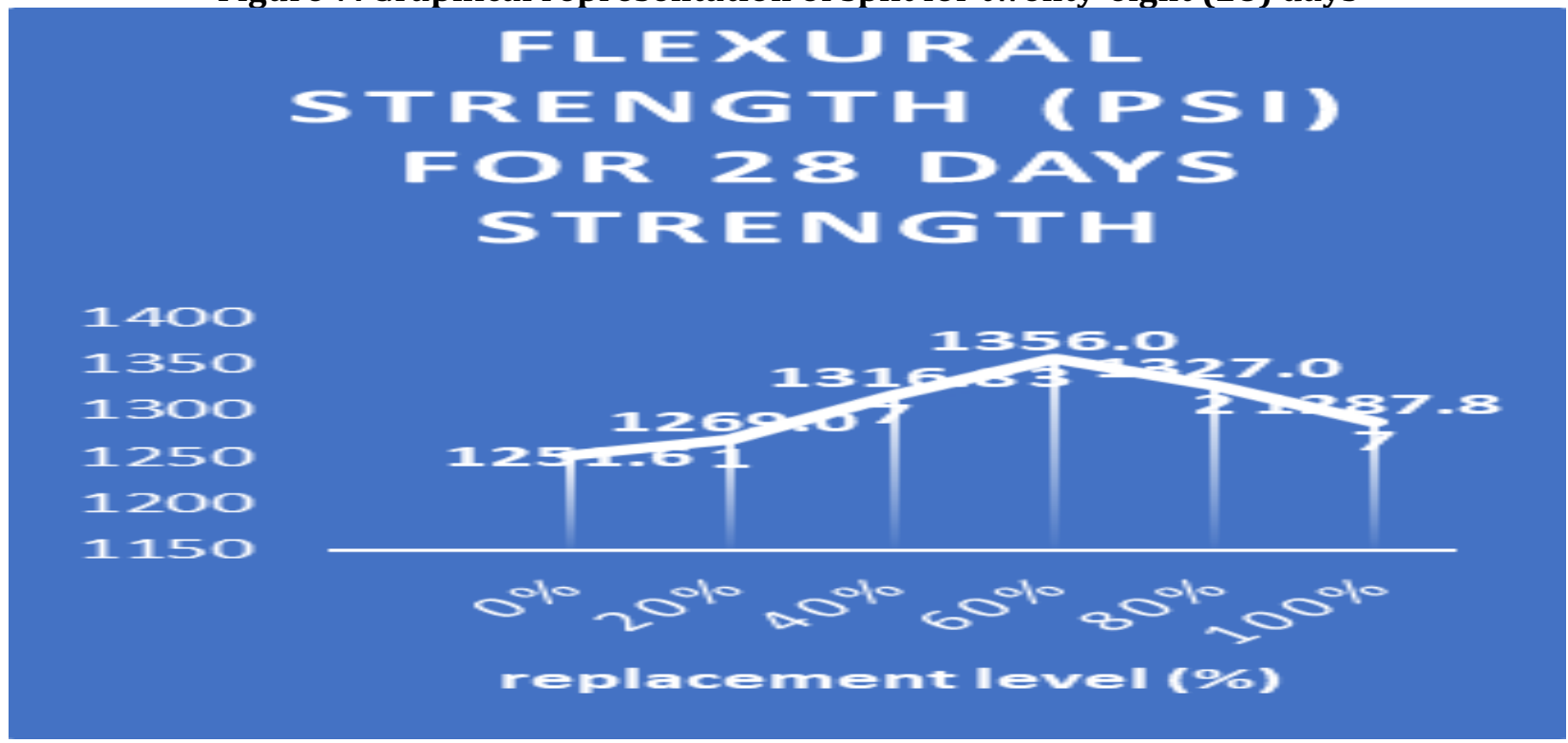

According to above table, the flexural strength test of a beam for Twenty, Fourthly, Sixty, Eighty and Hundred percent (\%) at Twenty-eight (28) day in which coarse aggregate was replaced by steel slag by above percent The flexural strength test for twenty-eight (28) days for sixty percent replacement is 1356.03 and which is highest then other replacement.

According to above figure, the flexural strength test of a beam for Twenty, Fourthly, Sixty, Eighty and Hundred percent (\%) at Twenty-eight (28) day in which coarse aggregate was replaced by steel slag by above percent The flexural strength test for twenty-eight (28) days for sixty percent replacement is 1356.03 and which is highest then other replacement.

\section{Slump Test}

In order to select or know workability of new solid, the droop trial was done and during that test was performed river liquid to bond ratio was kept in proportion and it was kept uniform for all the blend and mixes, for example, thirty-nine (39) percent (\%)

Table 7. Shows comparison of slump values

\begin{tabular}{|l|l|l|l|l|l|l|}
\hline & Cs $0 \%$ & Cs 20\% & Cs 40\% & Cs 60\% & Cs 80\% & Cs 100\% \\
\hline Combination & $0 \%$ & $20 \%$ & $40 \%$ & $60 \%$ & $80 \%$ & $100 \%$ \\
\hline Fall rate & $1.2 "$ & $1.25 "$ & $1.4 "$ & $1.50 "$ & $1.65 "$ & $1.9 "$ \\
\hline
\end{tabular}




\section{Figure 8. Shows comparison of slump value}

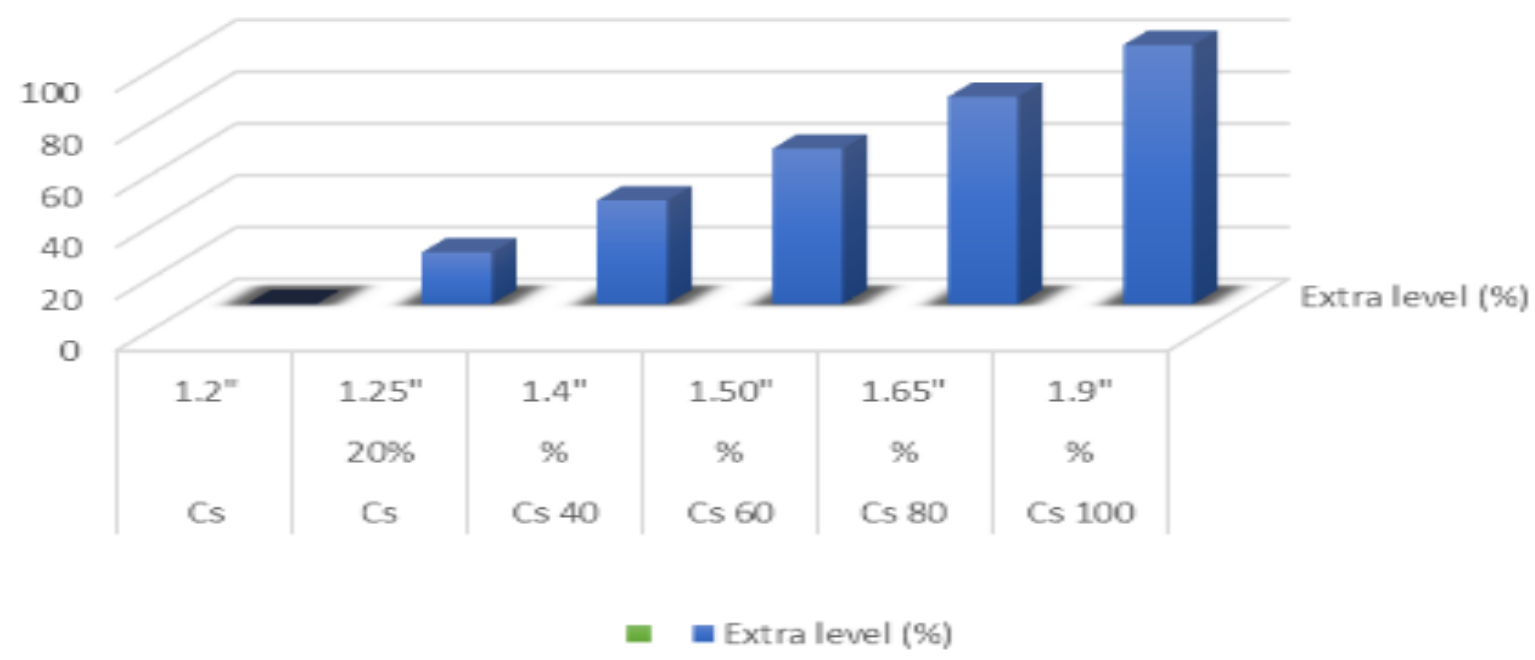

The slump was obtained and which was within limits of 1 inch to 2 inches, which is according to limit defined by ACI 21.

\section{Bulk of concrete}

The thickness of a considerable number concerning chambers was composed with and without by-product of a steel (steel slag) were resolved and after that, they were thought about for conclusion.

Table 8. Item weight concerning cement through various rates concerning steel slag/squanders for seven days

\begin{tabular}{|c|c|c|}
\hline Distinctive types of blend & Substitution Equal & $\begin{array}{c}\text { Seven } \\
\text { (7) days }\end{array}$ \\
\hline Cs & 0 & 147.83 \\
\hline Cs $20 \%$ & 20 & 148.54 \\
\hline Cs $40 \%$ & 40 & 149.31 \\
\hline Cs $60 \%$ & 60 & 150.07 \\
\hline Cs $80 \%$ & 80 & 150.69 \\
\hline Cs $100 \%$ & 100 & 150.73 \\
\hline
\end{tabular}

Figure 9. Graphical Representation for seven (7) days

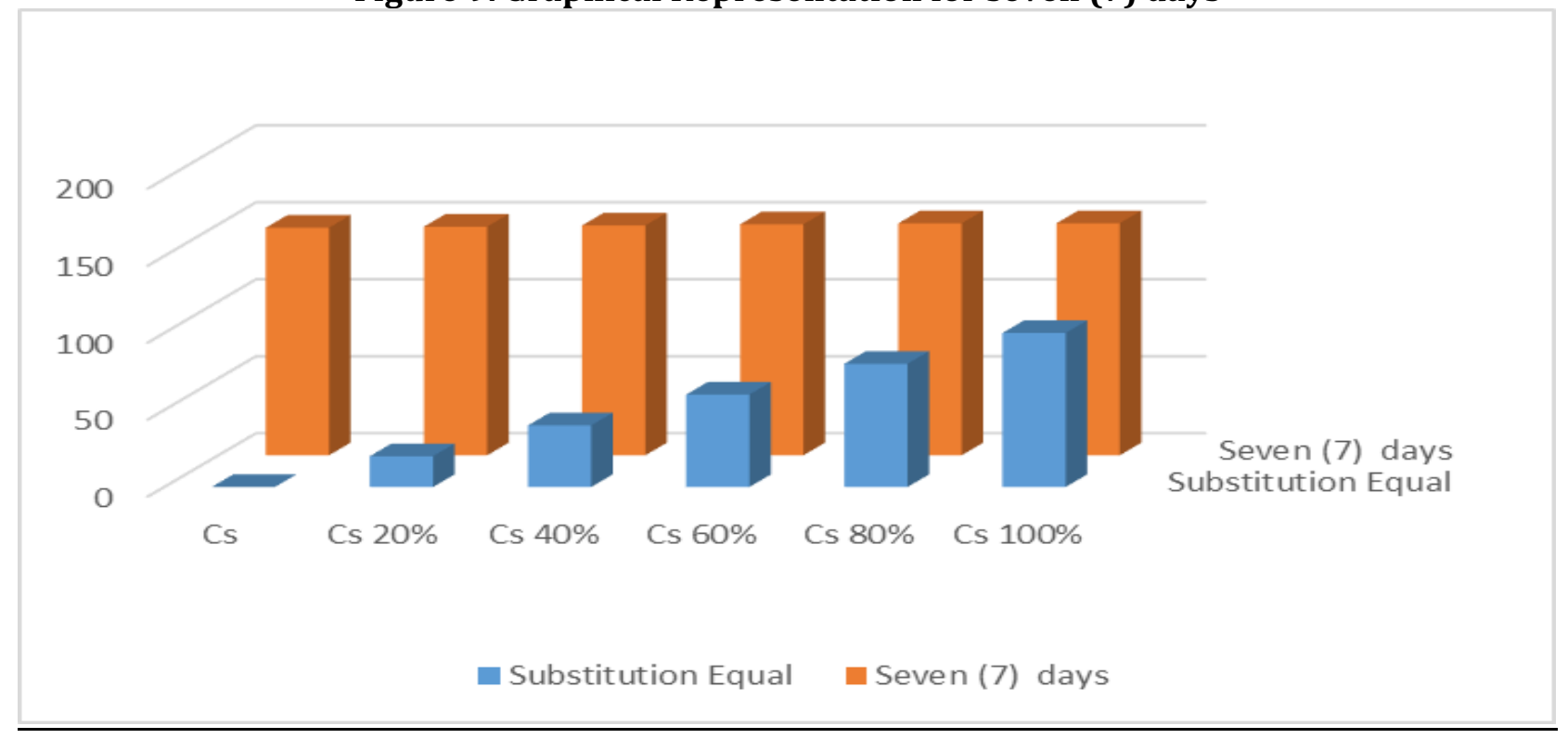


Table 9. For Fourteen days (14)

\begin{tabular}{|c|c|c|}
\hline Distinctive types of blend & Substitution Equal & $\begin{array}{c}\text { Fourteen } \\
\text { (14) days }\end{array}$ \\
\hline Cs & 0 & 147.79 \\
\hline Cs $20 \%$ & 20 & 148.59 \\
\hline Cs $40 \%$ & 40 & 149.29 \\
\hline Cs $60 \%$ & 60 & 150.05 \\
\hline Cs $80 \%$ & 80 & 150.72 \\
\hline Cs $100 \%$ & 100 & 150.81 \\
\hline
\end{tabular}

Figure 10. Graphical Representation for Fourteen days (14)

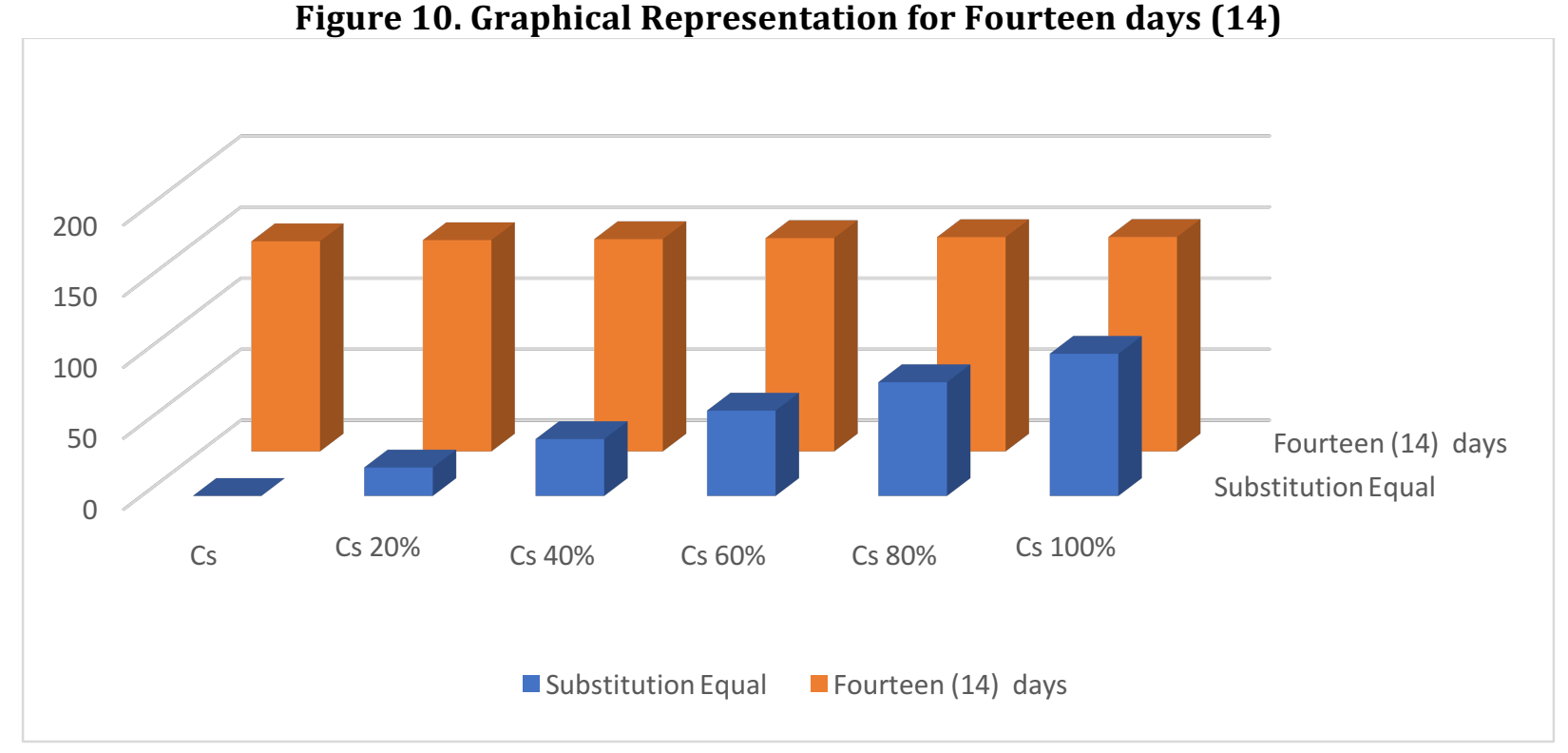

Table 10. For Twenty-Eight days (28)

\begin{tabular}{|c|c|c|}
\hline Distinctive types of blend & Substitution Equal & $\begin{array}{c}\text { Twenty-Eight } \\
(\mathbf{2 8 )} \text { days }\end{array}$ \\
\hline Cs & 0 & 147.81 \\
\hline Cs $20 \%$ & 20 & 148.57 \\
\hline Cs $40 \%$ & 40 & 149.27 \\
\hline Cs $60 \%$ & 60 & 150.10 \\
\hline Cs $80 \%$ & 80 & 150.73 \\
\hline Cs $100 \%$ & 100 & 150.92 \\
\hline
\end{tabular}

Figure 11. Graphical Representation for Twenty-eight days

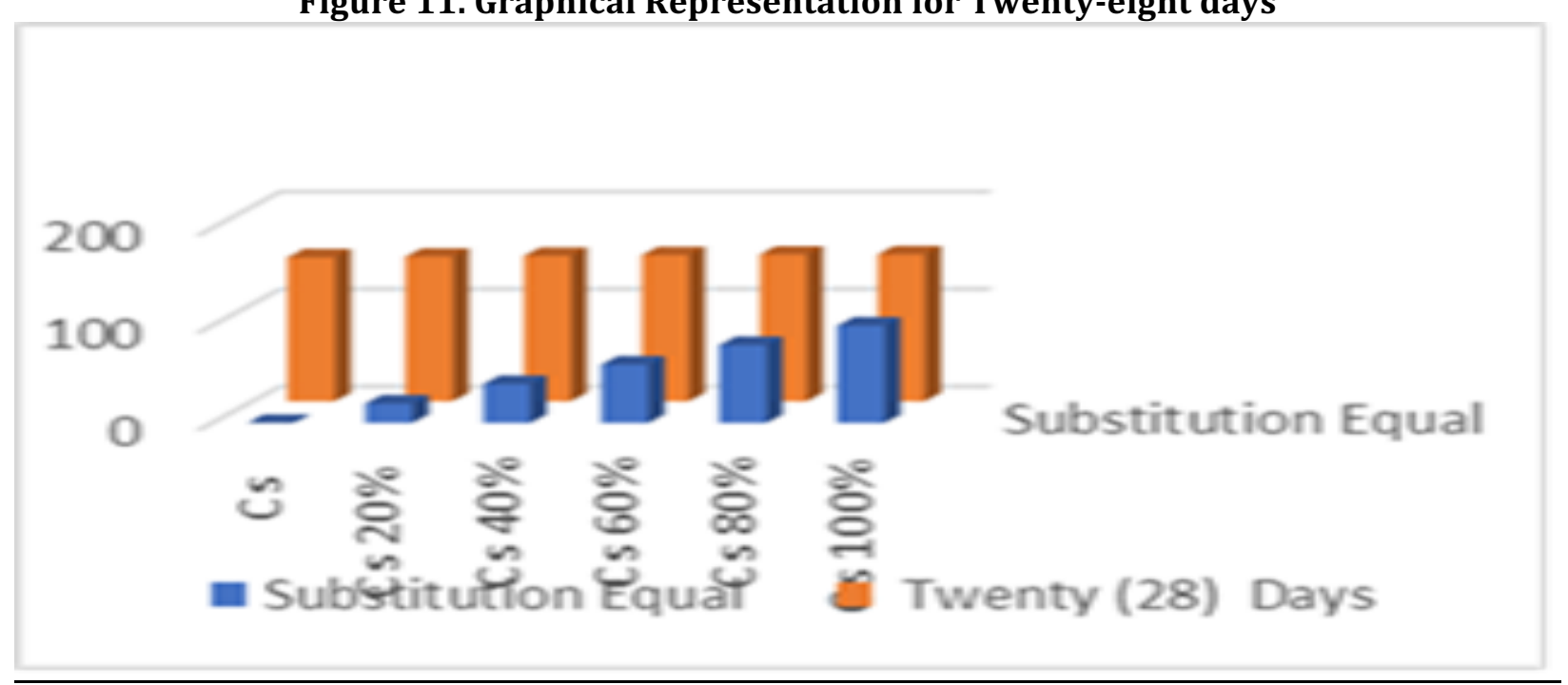




\section{Price investigation}

Price investigation is improved the situation the distinctive cement compost and without steel slag. The Price examination is composed per cubic meter of solid blend 1,1.78,1.36,0.52. The after-effect governor blend and solid blend composed with various rates of steel slag/squanders are appeared in the accompanying Schedule

Table 11. Showing Percent Price saving with different percentage usage of Steel Slag/waste concrete

\begin{tabular}{|c|c|c|c|}
\hline Successive Whole no & Classification & $\begin{array}{c}\text { Cost according to } \\
\text { Volume Rupees }\end{array}$ & $\begin{array}{c}\text { Allowance amount } \\
\text { Unwasteful }\end{array}$ \\
\hline 1 & Control Sample & 22,386 & $98 \%$ \\
\hline 2 & Cs $20 \%$ & $22,856.0$ & $23 \%$ \\
\hline 3 & Cs $40 \%$ & 99,050 & $419 \%$ \\
\hline 5 & Cs $60 \%$ & $23,648.40$ & $98 \%$ \\
\hline
\end{tabular}

\section{Reputation procedure of Steel Slag usage}

It is very common phenomena that a lot of by product steel is being obtained from steel manufacture and they ae being dumped into various place. In order to use that by-product of steel. There are various methods introduced, which not only re use that by product of steel in a useful material but it provides a good usage of steel waste from being dumped into various places

\section{Various usage of Steel Slag}

At present steel slag is used at various places due to its excellent characteristics and properties and on it basis it can be used at various places
1) All types of residential, commercial and industrial projects
2) Dams and other mass concrete works
3) Water retaining structures
4) Concrete roads and flyovers
5) Most suitable for marine constructions
6) Pre-cast concrete product
7) Foundations and piles construction 


\section{Benefit of steel slag}

The advantages of steel slag are given below

1) Its per unit cost of production is less

2) It has resistance for chloride \& sulphate attacks

3) It become compatible with every type of admixtures

4) It have better resistance against alkali-silica reaction

5) Its environmentally friendly.

Figure 12. Graphical Representation of a Percent Price saving with Steel slag/wastes concrete

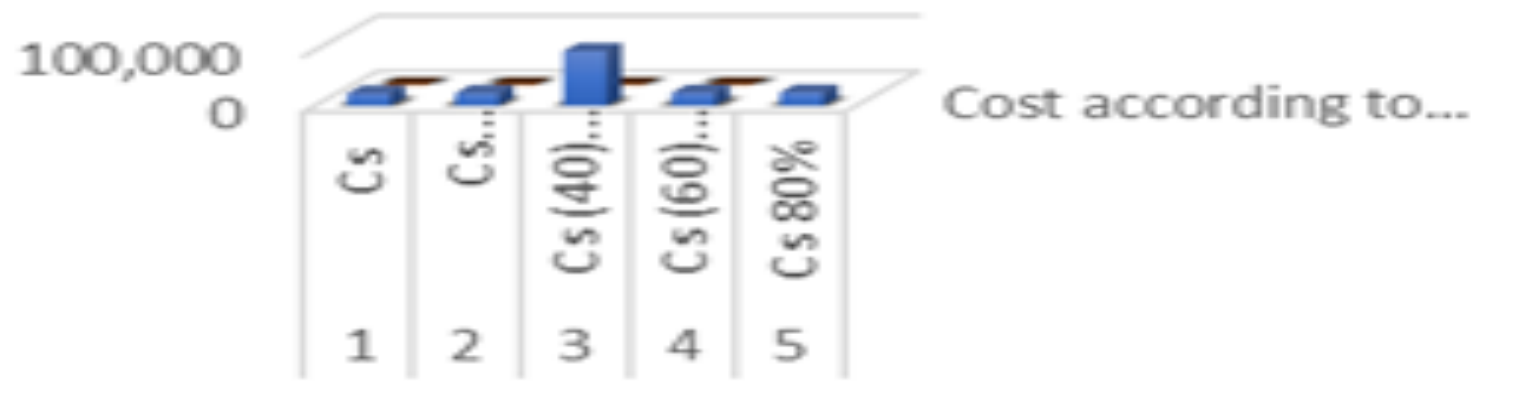

- Cost according to Volume Rupees Allowance amount unwasteful

E Allowance amount unwasteful -

\section{Shortcomings of Steel slag}

1) It has an environmental impact

2) It is difficult to be dumped

3) It have very sharp edges on its surface

\section{RESULT AND CONCLUSION}

In the light of the analyses done on the investigation of utilizing steel slag/squanders as an incomplete substitution of coarse total the accompanying perceptions are composed.

- The most astounding thickness accomplished with steel slag/squanders concrete with $100 \%$ substitution is marginally more than the thickness of governor trial.

- Workability/droop was expanding with expanding substance of steel slag.

- The compressive quality began to increment as the steel slag/squanders expanded with $60 \%$ substitution level.

- The most extreme increment in split elastic trial was seen with sixty (60) percent (\%) substitution of steel slag/squanders which is $11.67 \%$ and it is extra than the governor trial

- The Price of cement with forty (40) percent (\%) substitution of steel slag/squanders is diminished up to twenty-three (23) percent (\%).

- Exploitation of these sort of mechanical squanders in cement can help lessen the ecological effect of these squanders

\section{ENDORSEMENT}

- The utilization of by-product of a steel (steel slag) in concrete is prudent and can be utilized as an incomplete substitution of fine total up to $100 \%$. 
- The application of by-product of a steel (steel slag) in concrete is cost-effective and it can be used as a fractional addition of Mixture of rocks (coarse aggregate) near to about $100 \%$.

\section{RECOMMENDATION AIMED AT FORTHCOMING TASK}

In this examination, by product of a steel (steel slag) was supplanted with Mixture of small particles of grains(sand) in concrete. Albeit compressive quality trial and split trial were performed yet at the same time some examination work should be finished.

- The supplanting of by-product of a steel (steel slag) with fine total might be checked.

- By product of a steel (steel slag) solid strength should be checked at various \%ages of steel slag.

- Cement Grout composed with by product of a steel (steel slag) may likewise be checked.

\section{References}

Annadurai, A., and A. Ravichandran. 2014. "Development of mix design for high strength concrete with commixture s", IOSR journal of mechanical and civil engineering (IOSR-JMCE), vol. 10, issue-5:22-27

ASTM C 143.2000. "Standard Trial Technique for Slump of Hydraulic Cement Concrete, Philadelphi", PA. American Society for Trailing and Materials.

ASTM C 33. "Standard Technique for Mesh investigation of fine and Mixture of rocks (coarse aggregate)".

ASTM C 31. "Making and Curing Concrete Trial Specimens in the Field".

Bagel, L. 1998. "Strength and pore structure of Ternary Blended Cement Grouts Containing Blast Furnace Slag and Silica Fume. Cement and Concrete Research",Vol. 28:1011 -1020.

Berry, E.E., and V. M. Malhotra. 1980. "J. ACI, Proc., Vol. 77, No. 2: 59-73".

Bilodeau, A., V. M. Malhotra, and P. T. Seabrook, "Materials Technology”.

Burg, R. G., and B.W. Ost. 1994. "Engineering Belongings of Commercially Available High-Strength Concretes (Including Three-Year Data), Research and Development Bulletin RD104, Portland cement Association", 62.

Buil, M. and P. Acker. 1985. “Creep of silica fume concrete. Cement and Concrete Research", 15: 463-466.

Carette, G.G., and V.M. Malhotra. 1983. "Mechanical belongings, durability and drying shrinkage of Portland cement concrete incorporating silica fume. ASTM J. Cement, Concrete, Aggregates", 5(1): 3-13.

Chandra,S., and L. Berntsson. 2003. "Lightweight Aggregate Concrete-Science, Technology, and Applications: Noyes Publications", Norwich, NY:430.

Collepardi, M. 1984. "H20 reducers/retarders. In Concrete Commixture s Handbook: Belongings, Science, and Technology, Ramachandran, V.S”., Edn.:116-210. Noyes Publications, Park Ridge, NJ”.

Cramer, S.M., Hall, J. Parry. July 1995. "Effect of Optimized Total Aggregate Grading on Portland Cement Concrete for Wisconsin Pavements, Transportation Research Record, No. 1478, National Research Council”: 100-106. 